\title{
DIFFERENCES IN THE EFFECTS OF 0.05\% AND 0.1\% PROPOLIS FLAVONOIDS ON IN VITRO BIOFILM FORMATION BY STREPTOCOCCUS MUTANS FROM CHILDREN'S DENTAL PLAQUE
}

\author{
AGNES LINGGRIANI ${ }^{1}$, MOCHAMAD FAHLEVI RIZAL ${ }^{2 *}$, EVA FAUZIAH ${ }^{2}$, MARGARETHA SUHARSINI ${ }^{2}$
}

${ }^{1}$ Department of Pediatric Dentistry, Faculty of Dentistry, Universitas Indonesia, Jakarta 10430, Indonesia. ${ }^{2}$ Department of Pediatric Dentistry, Faculty of Dentistry, Universitas Indonesia, Jakarta 10430, Indonesia. *Email: Levipedo@gmail.com

Received: ???, Revised and Accepted: ???

\section{ABSTRACT}

Objective: This study was conducted to analyze the effects obtained with different concentrations (0.5 and $0.1 \%)$ of propolis flavonoids on in vitro biofilm formation by clinical Streptococcus mutans strains isolated from children's dental plaque.

Materials and Methods: S. mutans isolated from children's dental plaque was assayed for biofilm formation in 96-microwell plates using crystal violet.

Results: The effects on $S$. mutans biofilm formation were the same for propolis flavonoids administered at concentrations of 0.05 and $0.1 \%$ ( $>0.01$ ). Conclusion: A $0.05 \%$ propolis flavonoids concentration was deemed as effective as a $0.1 \%$ concentration at inhibiting $S$. mutans biofilm formation.

Keywords: Flavonoid, Propolis, Streptococcus mutans, Biofilm, Crystal violet.

(C) 2018 The Authors. Published by Innovare Academic Sciences Pvt Ltd. This is an open access article under the CC BY license (http://creativecommons. org/licenses/by/4. 0/) DOI: http://dx.doi.org/10.22159/ajpcr.2018.v11i2.22521

\section{INTRODUCTION}

Dental caries is a common oral health problem in children in different parts of the world. In Latin-American countries, the prevalence of child dental caries reached $60 \%$ in 2016 [1]. The caries prevalence of children aged 5-6 years in Southeast Asian countries in 2015 was even higher, ranging from $25 \%$ to $95 \%$, with an average of $75 \%$ [2]. In Indonesia, the prevalence of untreated active caries, based on Basic Health Research (RISKESDA) in 2013, was 53.2\% [3]. The prevalence of caries in children under 5 years of age in Indonesia is reported as $90 \%[4]$

Dental caries is a dynamic process that causes progressive damage to dental tissue (enamel, dentine, and cementum) and involves demineralization of inorganic parts of teeth and dissolution of the organic parts. The onset and progression of a carious lesion depend on factors such as hosts, microorganisms, and substrates that interact in recurrent cycles. Microorganisms form dental plaque, and the amount of plaque increases with time. Various strategies have been implemented to reduce caries rates, including strengthening the host, eliminating microorganisms, and changing dietary patterns [5].

Caries can be prevented by eliminating microorganisms through the administration of antibacterial agents. The antibacterial effect is intended to inhibit the bacterium Streptococcus mutans, which is the bacterial species that causes caries. A commonly used antibacterial agent is chlorhexidine, considered the gold standard because of its broad antibacterial spectrum [6]. However, the use of antibacterial agents derived from natural ingredients is increasing in popularity as an alternative. One source of these ingredients is propolis, a resin produced by bees.

Propolis has been widely used to treat a number of diseases. The composition of propolis depends on the ecosystem, climate, plant species, and bee species [7-9]. In Indonesia, the Trigona bee species are found in Sulawesi, and the main component of propolis from these bees is flavonoids $[7,8]$. Flavonoids derived from plants and fruits have known antibacterial, anti-inflammatory, and antioxidant effects and can prevent caries by antibacterial action $[10,11]$. Consequently, the antibacterial potency of flavonoids against various types of bacteria is now being widely studied. For example, studies on bacteria such as $E$. coli indicate that flavonoids can inhibit E. coli by influencing bacterial cell membrane interactions [10]. Several studies have revealed that flavonoids from various sources can also inhibit the growth of $S$. mutans. Flavonoids are known to inhibit the caries process by inhibiting the glucosyltransferase (GTF) enzyme, which in turn inhibits dental plaque formation and biofilm maturation, as well as tooth demineralization [12-14]

Clinical strains of $S$. mutans live under different environmental conditions that are experienced by $S$. mutans laboratory strains. S. mutans clinical strains live in the highly dynamic environment of the oral cavity, which increases their ability to survive and adapt. Therefore, these strains differ in physiological and biochemical properties and are typically more virulent than $S$. mutans laboratory strains $[15,16]$. The clinical strains also have the ability to grow 2-4 times faster, produce more acid, have higher caries activity, and form more biofilms when compared to the laboratory strains $[15,17,18]$. However, the study of the effectiveness of propolis flavonoids against $S$. mutans bacteria is still limited to laboratory strains.

The previous studies of minimal inhibitory levels indicated that propolis flavonoids inhibit the growth of laboratory strains of $S$. mutans, with a $0.1 \%$ concentration being the most effective at inhibiting $S$. mutans after $24 \mathrm{~h}$ of incubation [8]. Propolis flavonoids at various concentrations are known to inhibit the ATPase enzyme of $S$. mutans bacteria in vitro. Concentrations of $0.5,0.25,0.1,0.075$, and $0.05 \%$ propolis flavonoids gave the same antibacterial effect as $10 \%$ ethanol [19]. The aim of the present study was, therefore, to determine whether 0.05 and $0.1 \%$ concentrations of propolis flavonoids would inhibit the in vitro biofilm formation by clinical S. mutans strains isolated from children's dental plaque.

\section{MATERIALS AND METHODS}

Ethical statement

This study was approved by the Ethical Committee of the Faculty of Dentistry Universitas Indonesia (Number: 42/ethical approval/FKGUI/ VII/2017; protocol number: 050390517). 


\section{Flavonoid extraction from propolis}

Flavonoids from raw propolis obtained from Trigona sp. Beehives in Luwu, North Sulawesi, were extracted using a maceration method [8]. $1 \mathrm{~kg}$ of Trigona sp. propolis was transferred to an electric macerator, and $5 \mathrm{~L}$ of $95 \%$ ethanol was added as a solvent. Maceration was conducted by stirring 12 times for $15 \mathrm{~min}$, with a grace period of $5 \mathrm{~min}$ between stirring, followed by immersion for $120 \mathrm{~h}$. The material was then filtered by gravity through filter paper to separate the filtrate from the dregs. The ethanol in the filtrate was evaporated on a porcelain plate, leaving a thick extract. The extract was put into an Erlenmeyer flask, $500 \mathrm{~mL}$ of toluene was added, and the mixture was stirred until dissolved. A $1.5 \mathrm{~L}$ volume of a water: ethanol solution $(2: 1, \mathrm{v} / \mathrm{v})$ was added, and the mixture was again stirred until homogeneous. After standing for $24 \mathrm{~h}$, the solution was transferred to a separatory funnel and allowed to form 2 layers. The bottom solution was removed and evaporated to obtain a viscous extract.

The 0.05 and $0.1 \%$ propolis flavonoid solutions were prepared by diluting the extract with distilled water (i.e., 0.05 and $0.1 \%$ propolis flavonoid preparations were obtained by dissolving 5 and $10 \mathrm{mg}$ of the extract, respectively, in $10 \mathrm{~mL}$ sterile distilled water).

\section{Subjects}

The participants were healthy children 6-9 years of age. Each subject had fully erupted first permanent molars, and no caries was visible on the buccal surface of upper first permanent molars and/or on the lingual surface of the lower first permanent molars.

\section{Sample collection}

Plaque samples were taken using sterile cotton swabs from the buccal surfaces of the upper first permanent molars and the lingual surfaces of the lower first permanent molars, using two sweeps on each surface. The plaque was then inserted into Eppendorf tubes containing $1 \mathrm{~mL}$ of phosphate-buffered saline (PBS) and placed in a cooler box.

\section{Bacterial culture and identification}

A $25 \mu \mathrm{L}$ volume of solution was taken from the Eppendorf tubes with a pipette and cultured on TYS20B medium in a Petri dish. The Petri dish was inserted into an anaerobic jar containing an atmosphere of $5 \% \mathrm{CO}_{2}, 10 \% \mathrm{H}_{2}$, and $85 \% \mathrm{~N}_{2}$ gas and incubated at $37^{\circ} \mathrm{C}$ for $24 \mathrm{~h}$. Successful culture of $S$. mutans culture on TYS20B agar was confirmed by a visualization method and by microscopy following gram staining. From each culture of $S$. mutans on TYS20B agar, one colony was taken and transferred to a test tube containing $5 \mathrm{~mL}$ TYS broth solution for culture on liquid medium. After $24 \mathrm{~h}$, the optical density (OD) was measured with a microplate reader at a $450 \mathrm{~nm}$ wavelength. The obtained OD value was converted to calculate the number of colonies (colony-forming units $/ \mathrm{mL}$ ). The culture was then diluted to obtain a concentration of $1 \times 10^{6}$ bacteria $/ \mathrm{mL}$, which was then used for the biofilm assay.

\section{Biofilm assay}

A $100 \mu \mathrm{L}$ volume of bacterial culture in diluted TYS Broth medium and $100 \mu \mathrm{L}$ of prepared propolis flavonoids were then added to each well of a 96-microwell plate to give a total volume of $200 \mu \mathrm{L}$ per well. Negative control wells of TYS Broth medium alone and positive control wells containing the $S$. mutans ATCC 25175 laboratory strain in TYS broth medium were also included. Duplicate wells were prepared for all treatments. The 96-microwell plate was incubated at $37^{\circ} \mathrm{C}$ in an anaerobic jar containing $5 \% \mathrm{CO}_{2}, 10 \% \mathrm{H}_{2}$, and $85 \% \mathrm{~N}_{2}$ gas. After $24 \mathrm{~h}$ of incubation, the bacterial cells that did not form biofilms on the well base (i.e., the planktonic portion) were removed, and each well was washed twice with $200 \mu \mathrm{L}$ PBS. A $200 \mu \mathrm{L}$ volume of $0.5 \%$ crystal violet was then added and incubated at $37^{\circ} \mathrm{C}$ for $15 \mathrm{~min}$. The remaining crystal violet solution was discarded, the biofilm was washed once with $200 \mu \mathrm{L}$ PBS, and $200 \mu \mathrm{L}$ of $96 \%$ ethanol solution was added to each well. The absorbance OD of the formed biofilm was then measured at $490 \mathrm{~nm}$ using a microplate reader.

\section{Statistical analysis}

Data were analyzed by an unpaired t-test, with significance set at $\mathrm{p}<0.01$, to determine the difference in the effects of 0.5 and $0.1 \%$ propolis flavonoids on biofilm formation by clinical $S$. mutans strains isolated from children's dental plaque.

\section{RESULTS}

The OD values in the flavonoids-treated wells were larger than the OD values for the negative control (mean $\mathrm{OD}=0.054$ ), which was run as a blank. The OD of this blank was set to $\mathrm{OD}=0$, and all $\mathrm{OD}$ values in the treatment groups and the positive control were measured against that blank.

The mean $O D$ values for the $0.5 \%$ propolis flavonoids $(O D=0.047)$ and $0.1 \%$ propolis flavonoids $(\mathrm{OD}=0.049)$ treatments were smaller than the mean OD value for the positive control (OD $=0.061$ ), as shown in Table 1. The statistical analysis shown in Table 2 indicates no significant difference $(\mathrm{p}=0.810)$ between the effects of $0.5 \%$ and $0.1 \%$ propolis flavonoids on in vitro biofilm formation by $S$. mutans strains isolated from children's dental plaque.

\section{DISCUSSION}

The aim of this research was to analyze the effects of 0.5 and $0.1 \%$ concentrations of propolis flavonoids on in vitro biofilm formation by clinical $S$. mutans strains isolated from children's dental plaque. This study is a follow-up to a similar previous study that investigated propolis flavonoids effects on $S$. mutans laboratory stocks, but the aim of the present study was to more closely approximate the organisms that actually populate the oral cavity. The $S$. mutans laboratory strains have been repeatedly subcultured for years under optimal conditions with many organic and inorganic growth factors [15]. Research using laboratory strains should be confirmed using clinical strains to ensure that in vitro results validly represent those obtained with in vivo strains [15].

In this study, we used $S$. mutans clinical strain samples derived from dental plaques taken from healthy subjects. The objective was to isolate S. mutans strains that had grown in culture conditions that were always different and to obtain a situation close to the actual oral environment. The oral environment is always changing, so S. mutans strains in the oral cavity will show an improved ability to adapt and survive. Previous work has shown that $S$. mutans clinical strains can grow 2-4 times faster and produce more acids when compared to laboratory strains [15]. Other studies have also suggested that $S$. mutans clinical strains have higher caries activity when compared with $S$. mutans laboratory strains [17].

Plaque was sampled using a sterile cotton swab with slightly bent ends. In accordance with previous literature, the use of a cotton bud or cotton swab is an effective method for plaque sampling and for evaluating S. mutans in the plaque [20]. The plaque was taken from the buccal surface of the maxillary first permanent molars and the lingual surfaces of the mandibular first permanent molars, as the posterior molar teeth are areas where the $S$. mutans bacterial colonies are most commonly formed. The more anterior teeth tend to have fewer S. mutans colonies [21]. In addition, S. mutans colonies are also more available on the buccal/lingual surfaces than on the occlusal and proximal surfaces [22]. The plaque taken on each of the surfaces represented two separate swabs, as a larger number of swabs per surface increased the amounts of $S$. mutans collected [22].

The accumulation of $S$. mutans on tooth surfaces is the main etiology of caries. Therefore, efforts continue to prevent caries by eliminating S. mutans bacteria from the teeth. One way to do this is by treatment with antibacterial agents. The gold standard antibacterial is chlorhexidine [6]. However, antibacterial ingredients that are sourced from natural materials are increasingly being developed and in demand. The aim of the present study was to investigate a propolis flavonoids extract as a natural antibacterial agent [7]. 
Propolis is a material collected by bees from various plants and mixed with secretions from the bee hypopharyngeal gland. Propolis has known antibacterial properties and has been widely used for various purposes in clinical trials in the dentistry field. The propolis flavonoids are important compounds and active biologic components, so flavonoids are believed to play an important role in the observed antibacterial properties of propolis $[23,24]$. The flavonoids used in the present study were derived from raw propolis obtained from the honeycombs of Trigona sp. in the Luwu area of North Sulawesi. This propolis was extracted by a maceration method, followed by chromatography, to yield $10.61 \mathrm{~g}$ of flavonoids from $100 \mathrm{~g}$ of crude propolis. This yield is consistent with other reports in the literature of flavonoid percentages ranging from $5 \%$ to $26 \%$ in crude propolis [25].

Flavonoids are found in a variety of plants, including fruits and vegetables, and they are compounds with known antibacterial properties. Flavonoids are natural compounds that have a low toxicity, are safe to eat, and rarely elicit allergic reactions [26]. The propolis flavonoids extract used in this study was administered at concentrations of 0.1 and $0.05 \%$. The $0.1 \%$ concentration was chosen because previous studies had reported this concentration as the most effective at inhibiting the growth of $S$. mutans bacteria [8]. The $0.05 \%$ concentration was chosen because it was the smallest concentration that previously gave an equally good antibacterial effect when compared to four higher concentrations [19].

In this study, samples of children's plaque containing $S$. mutans were cultured on TYS20B agar medium. This medium is one of the most selective media for $S$. mutans. Culturing was done on a selective medium to obtain only $S$. mutans bacteria that could grow on that agar medium. Of the selective media for $S$. mutans, TYS20B medium has the best sensitivity, so it was used in this study [27].

The growth of $S$. mutans was confirmed by visualization and gram staining after culture in TYS20B medium. The visualization identified small yellowish-white colonies characteristic of $S$. mutans. Microscopy examination confirmed a morphology of chains of purple, round microorganisms, consistent with S. mutans [28].

The $S$. mutans strains were cultured in the selective TYS broth liquid medium to avoid contamination with other bacteria during incubation. The amounts of bacteria were determined indirectly by turbidity measurements made after incubation in TYS broth media for $24 \mathrm{~h}$. Measurements were also made using by culturing bacteria in 96-microwell plates, followed by OD determinations. After $24 \mathrm{~h}$, the bacteria were already in the stationary phase, so the bacterial count remains relatively unchanged [29]. Therefore, the bacterial counts were conducted after $24 \mathrm{~h}$.

Biofilm assays were performed when the biofilm formation process had reached the maturation stage. The 96-microwell plates used for the biofilm test were incubated for $24 \mathrm{~h}$, as this is the ideal time for biofilm incubation according to the available literature, as it improves the maturation and biofilm adhesion [30]. Other literature also indicates that biofilm maturation is achieved after $24 \mathrm{~h}$ and that bacterial growth in the biofilm has ceased and stabilized by that time [31,32].

In the biofilm assays, all the treatment groups showed larger OD values compared to the negative control blank, confirming the growth and biofilm formation of the $S$. mutans clinical strains isolated here. Bacterial growth and biofilm formation will increase the turbidity of the solution within the well, while crystal violet will stain the biofilm. A larger biofilm formation will intensify the purple color and increase the OD $[29,30]$. The biofilm assay results, as shown in Table 1, indicate that the mean OD was smaller for the propolis flavonoids treatment groups ( $S$. mutans clinical strains+medium+propolis flavonoids) than for the positive control (S. mutans ATCC 25175+medium). The formation of biofilms by the $S$. mutans clinical strains was clearly inhibited by propolis flavonoids, whereas the formation of biofilms in the positive control laboratory strain was not affected.

The $S$. mutans clinical strains have a higher virulence, are able to grow 2-4 times faster, and form more biofilms when compared with laboratory strains $[15,18]$ Therefore, in the treatment groups, the formation of biofilms will be faster and more extensive for the S. mutans clinical strains than for the laboratory strains. The biofilm formation was smaller in the treatment groups with the $S$. mutans clinical strains, as indicated by the smaller OD value, than in the positive control (a less virulent $S$. mutans laboratory strain). This OD value decreased due to the antibacterial effect of the propolis flavonoids, which inhibited the formation of biofilms by the $S$. mutans clinical strains. Therefore, propolis flavonoid can be deemed effective against the growth of S. mutans clinical strains.

The results shown in Table 2 indicate no significant difference between propolis flavonoid concentrations of 0.05 and $0.1 \%$ in terms of in vitro biofilm formation by $S$. mutans isolated from children's dental plaque. Therefore, both concentrations of propolis flavonoids were equally effective at inhibiting biofilm formation. This finding agrees with those of the previous studies reporting that propolis flavonoids at various concentrations $(0.5,0.25,0.1,0.075$, and $0.05 \%)$ had the same antibacterial effect in terms of inhibiting the $S$. mutans ATPase. These five levels of propolis flavonoid concentrations also gave the same antibacterial effect as observed with a $10 \%$ ethanol control [19].

Previous studies also indicated that a propolis flavonoids concentration of $0.1 \%$ was the most effective concentration for inhibiting the growth of $S$. mutans bacteria after $24 \mathrm{~h}$ incubation, whereas a $0.05 \%$ concentration gave a smaller effect [8]. In the present study, with the same incubation period of $24 \mathrm{~h}$, the $0.05 \%$ concentration was just as effective as the $0.1 \%$ concentration at inhibiting S. mutans biofilm formation. The differences in the findings of these two studies might reflect differences in the bacterial culture medium used. Selective TYS20B and TYS broth media were used in the present study, whereas using glucose nutrient agar, medium was used in the previous study [8].

The results of this study support the conclusion that the inhibition of $S$. mutans biofilm formation by propolis flavonoids could involve inhibition of the GTF enzyme, as previously postulated [10-12]. This inhibition of GTF would reduce glucan production, thereby disrupting the coadhesion process and biofilm maturation of $S$. mutans. A propolis flavonoids concentration of $0.05 \%$ is recommended for antibacterial purposes because this was the smallest effective concentration and would therefore be expected to have the fewest pharmacological side effects.

Toxicity tests on the flavonoids derived from propolis are still necessary, even though flavonoids are generally considered to be low-toxicity compounds and seldom trigger allergic reactions. This

Table 1: Mean OD treatment and control group

\begin{tabular}{ll}
\hline Treatment and control group & Mean OD \\
\hline $0.05 \%$ propolis flavonoids & 0.047 \\
$0.1 \%$ propolis flavonoids & 0.049 \\
Positive control & 0.061 \\
Negative control & 0 \\
\hline
\end{tabular}

OD: Optical density

Table 2: S. Mutans biofilm formation

\begin{tabular}{llll}
\hline Propolis flavonoids (\%) & $\mathbf{n}$ & Mean OD value \pm SD & $\mathbf{p}$ \\
\hline 0.05 & 16 & $0.047 \pm 0.025$ & 0.810 \\
0.1 & 16 & $0.049 \pm 0.023$ & \\
\hline
\end{tabular}

Unpaired t-test; meaning value based on $\mathrm{p}<0.01$.

S. mutans: Streptococcus mutans, OD: Optical density 
research represents a next step in the future use of propolis flavonoids as antibacterials, in the form of mouthwashes, toothpastes, or other preparations, for the prevention of caries in humans, and especially in children.

\section{CONCLUSIONS}

These research findings support the conclusion that propolis flavonoids suppress in vitro biofilm formation by $S$. mutans isolated from children's dental plaque. Notably, a $0.05 \%$ concentration was equally as effective as a $0.1 \%$ concentration at suppressing biofilm formation by the clinical S. mutans strains investigated. Further research is needed to determine the toxicity and sensitivity responses of the oral mucosa to propolis flavonoids to support the use of these flavonoids as antibacterial agents in humans.

\section{ACKNOWLEDGMENTS}

All authors have made substantive contributions to this study and/or manuscript, and all have reviewed the final paper before its submission. This study was funded by Directorate of Research and Community Service Universitas Indonesia in 2017.

\section{CONFLICTS OF INTEREST}

The authors declare that they have no conflict of interest.

\section{AUTHORS CONTRIBUTION}

This study was designed, conducted, and coordinated by Mochamad Fahlevi Rizal, Eva Fauziah, Margaretha Suharsini as the principal investigator, provided conceptual and technical guidance for all aspects of the project. Agnes Linggriani performed, analyzed the data and write the manuscript.

\section{REFERENCES}

1. Gimenez T, Bispo BA, Souza DP, Viganó ME, Wanderley MT, Mendes FM, et al. Does the decline in caries prevalence of latin American and Caribbean children continue in the new century? Evidence from systematic review with meta-analysis. PLoS One 2016;11:e0164903.

2. Duangthip D, Gao SS, Chin E, Lo M, Chu CH. Early childhood caries among 5-to 6-year-old children in Southeast Asia. Int Dent J 2017;67:98-106.

3. Badan Penelitian dan Pengembangan. Riset Kesehatan Dasar. Jakarta: 2013.

4. Badan Penelitian dan Pengembangan. Riset Kesehatan Dasar. Jakarta: 2007.

5. Yip K, Smales R. Oral diagnosis and treatment planning: Part 2. Dental caries and assessment of risk. Br Dent J 2012;213:59-66.

6. Thomas A, Thakur SR, Shetty SB. Anti-microbial efficacy of green tea and chlorhexidine mouth rinses against Streptococcus mutans, Lactobacilli spp. and Candida albicans in children with severe early childhood caries: A randomized clinical study. J Indian Soc Pedod Prev Dent 2016;34:65-70.

7. Marcucci M. Propolis : Chemical composition, biological properties and therapeutic activity. Apidologie 1995;26:83-99.

8. Sabir A. Aktivitas antibakteri flavonoid propolis Trigona sp terhadap bakteri Streptococcus mutans (in vitro). Maj Ked Gi 2005;38:135-41.

9. Figueiredo FJ, Dias-Souza MV, Nascimento EA, De Lima LR. Physicochemical characterization and flavonoid contents of artisanal Brazilian green propolis. Int J Pharm Pharm Sci 2015;7:64-8.
10. Wu T, He M, Zang X, Zhou Y, Qiu T, Pan S, et al. A structure-activity relationship study of flavonoids as inhibitors of $E$. Coli by membrane interaction effect. Biochim Biophys Acta 2013;1828:2751-6.

11. Pujirahayu N, Ritonga $\mathrm{H}$, Uslinawaty Z. Properties and flavonoids content in propolis of some extraction method of raw propolis. Int $\mathrm{J}$ Pharm Sci 2014;6:338-40.

12. Ferrazzano GF, Amato I, Ingenito A, De Natale A, Pollio A. Anticariogenic effects of polyphenols from plant stimulant beverages (cocoa, coffee, tea). Fitoterapia 2009;80:255-62.

13. Ferrazzano GF, Amato I, Ingenito A, Zarrelli A, Pinto G, Pollio A, et al. Plant polyphenols and their anti-cariogenic properties: A review. Molecules 2011;16:1486-507.

14. Awadalla HI, Ragab MH, Bassuoni MW, Fayed MT, Abbas MO. A pilot study of the role of green tea use on oral health. Int J Dent Hyg 2011;9:110-6.

15. Vadeboncoeur C, Trahan L. Comparative study of Streptococcus mutans laboratory strains and fresh isolates from carious and caries-free tooth surfaces and from subjects with hereditary fructose intolerance. Infect Immun 1983;40:81-90.

16. Kaur G, Rajesh S, Princy SA. Plausible drug targets in the Streptococcus mutans quorum sensing pathways to combat dental biofilms and associated risks. Indian J Microbiol 2015;55:349-56.

17. Kohler B, Krasse B. Human strains of mutans streptococci show different cariogenic potential in the hamster model. Oral Microbiol Immunol 1990;5:177-80.

18. Palmer SR, Miller JH, Abranches J, Zeng L, Lefebure T, Richards VP, et al. Phenotypic heterogeneity of genomically-diverse isolates of Streptococcus mutans. PLoS One 2013;8:e61358.

19. Erlianda D. Efek Antibakteri Flavonoid Propolis Berbagai Konsentrasi dan Etanol terhadap Aktivitas ATPase Streptococcus mutans. Depok: Universitas Indonesia; 2017

20. Keene HJ. Sampling of cariogenic microorganisms in human populations. Oral Microbiol Immunol 1986;1:7-14

21. Lindquist B, Emilson CG. Dental location of Streptococcus mutans and Streptococcus sobrinus in humans harboring both species. Caries Res 1991;25:146-52.

22. Wennerholm K, Lindquist B, Emilson CG. The toothpick method in relation to other plaque sampling techniques for evaluating mutans streptococci. Eur J Oral Sci 1995;103:36-41.

23. Koo H, Rosalen PL, Cury JA, Park YK, Bowen WH. Effects of compounds found in propolis on Streptococcus mutans growth and on glucosyltransferase activity. Antimicrob Agents Chemother 2002;46:1302-9

24. Duailibe SA, Gonçalves AG, Ahid FJ. Effect of a propolis extract on Streptococcus mutans counts in vivo. J Appl Oral Sci 2007;15:420-3.

25. Kosalec I, Bakmaz M, Pepeljnjak S, Vladimir-Knezević S. Quantitative analysis of the flavonoids in raw propolis from Northern Croatia. Acta Pharm 2004;54:65-72.

26. Havsteen BH. The biochemistry and medical significance of the flavonoids. Pharmacol Ther 2002;96:67-202

27. Wan AK, Seow WK, Walsh LJ, Bird PS. Comparison of five selective media for the growth and enumeration of Streptococcus mutans. Aust Dent J 2002;47:21-6.

28. Finegold S, Martin W. Bailey and Scoott's Diagnostic Microbiology. $6^{\text {th }}$ ed. St. Louis: CV. Mosby; 1982

29. Madigan M, Bender K, Buckley D, Martinko J, Stahl D. Brock Biology of Microorganisms. 14 $4^{\text {th }}$ ed. Harlow: Pearson; 2014. p.140-8.

30. Metzler A. Developing a Crystal Violet Assay to Quantify Biofilm Production Capabilities of Staphylococcus aureus. Colombus: The Ohio State University; 2016.

31. Ma R, Sun M, Wang S, Kang Q, Huang L, Li T, et al. Effect of highfructose corn syrup on the acidogenicity, adherence and biofilm formation of Streptococcus mutans. Aust Dent J 2013;58:213-8.

32. Seneviratne CJ, Zhang CF, Samaranayake LP. Dental plaque biofilm in oral health and disease. Chin J Dent Res 2011;14:87-94. 